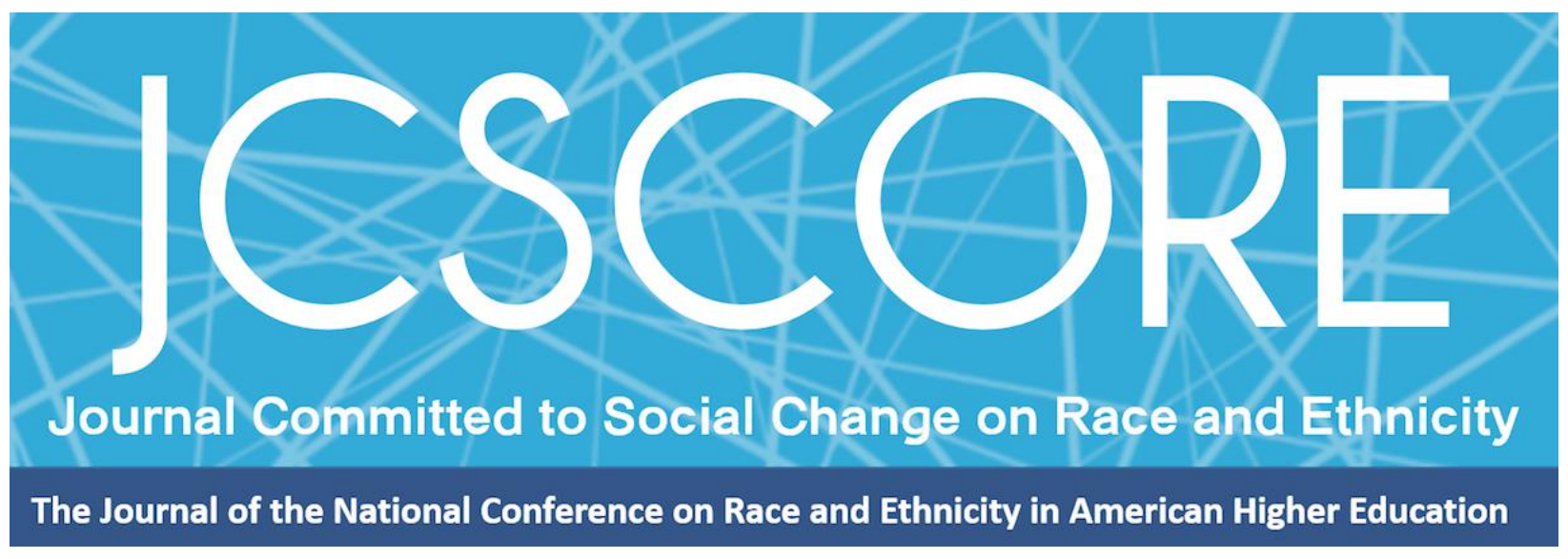

\title{
FURTHER CONTEXTUALIZING RACIAL IDENTITY: MULTIRACIAL STUDENTS AT HISPANIC-SERVING INSTITUTIONS
}

\author{
Nik Cristobal \\ University of Pittsburgh \\ Marc P. Johnston-Guerrero \\ The Ohio State University \\ Gina A. Garcia \\ University of Pittsburgh
}

Journal Committed to Social Change on Race and Ethnicity

Volume 7, Issue 2 | 2021

\section{Copyright and Open Access}

(C) 2021 Nik Cristobal, Marc P. Johnston-Guerrero, Gina A. Garcia

\section{cc) (i) (2) (2)}

This work is licensed under a Creative Commons Attribution-NonCommercial-ShareAlike 4.0 International License. Permission of the authors is required for distribution and for all derivative works, including compilations and translations. Quoting small sections of text is allowed as long as there is appropriate attribution and the article is used for non-commercial purposes.

The Journal Committed to Social Change on Race and Ethnicity (ISSN 2642-2387) is published by the National Conference on Race and Ethnicity (NCORE), a production of the University of Oklahoma, in partnership with the University of Oklahoma Libraries. 


\title{
Further Contextualizing Racial Identity: Multiracial Students at Hispanic-Serving Institutions
}

\author{
Nik Cristobal \\ University of Pittsburgh \\ Marc P. Johnston-Guerrero \\ The Ohio State University \\ Gina A. Garcia \\ University of Pittsburgh
}

\begin{abstract}
Despite the recent growth of literature on multiracial college students, there is still limited understanding about multiracial students at Minority-Serving Institutions (MSIs). This qualitative study explores the interplay of racialized identity and the unique contexts of Hispanic-Serving Institutions (HSIs) using data from eight multiracial students attending two HSIs in the Midwest. Findings explore how students made sense of their multiracial identities within specific ecological contexts of HSls, including a mesosystem of diversity and inclusion and an exosystem of Latinidad. Overall, multiracial students generally felt included and provide a promising platform to better understand the unique positioning of HSls in serving an increasingly diverse student body.
\end{abstract}

The 2020 U.S. Census indicates that approximately 33.8 million people in the United States identified with two or more racial groups, representing a $276 \%$ increase from 2010 (Jones et al., 2021). This growth is also being witnessed across higher education (Johnston-Guerrero \& Wijeyesinghe, 2021); yet the research with this population has tended to focus on Racially White Institutions (RWIs) ${ }^{1}$. Concurrently, there has been recent growth in enrollments at and research with Minority-Serving

\footnotetext{
${ }^{1}$ Following Garcia's (2019) compelling theoretical explanation of how different institutions are racialized, we use "Racially White Institutions" (RWIs) to acknowledge the powerful and lasting influence of racialization even if institutions are not compositionally "predominately" white. In this article, RWIs refer to all non-Minority-Serving Institutions (MSIs), although we recognize the complexities of HSIs themselves transitioning from RWIs to MSIs and discuss these complexities throughout. Further, the use of lowercase "white" is a way to de-center whiteness and challenge predetermined definitions of racial and ethnic categories that ideologically segregate People of Color, including mixed race people.
} 
Journal Committed to Social Change on Race and Ethnicity | Volume 7, Issue 2 | 2021

Institutions (MSIs), particularly Hispanic-Serving Institutions (HSIs; e.g., Garcia et al., 2019a; Cuellar, 2019). While emerging scholarship has looked at the experiences of non-Latin* ${ }^{*}$ students $^{2}$ at HSIs (e.g., Abrica et al., 2020; Serrano, 2020), the research has generally overlooked multiracial populations. Therefore, the purpose of this study was to focus on the identities of eight multiracial students attending two HSIs in the Midwest. More specifically, the relationship between multiracial students' identities and the HSI context is explored. Two research questions guided the study: (a) How do multiracial students at HSIs see their identities reflected or not reflected at their institution? And, (b) how might the HSI context influence these identities? The authors operationalize reflection as the interactions between individuals and their organizational context with a priority given to individual perceptions and experiences as accessed through interviews.

\section{Literature Review}

The literature on multiracial identity and experiences has blossomed in the past decades, evidenced by an expanding multidisciplinary field of Critical Mixed Race Studies (Daniel et al., 2014). This expansion has also been witnessed in the field of higher education and student affairs specifically (e.g., Chang, 2014; Harris, 2016, 2017, 2019; Johnston-Guerrero et al., 2020; Museus et al., 2015, 2016; Osei-Kofi, 2012; Renn, 2004, 2008, 2009). However, much of the literature remains limited due to its focus on multiracial students at RWls. For instance, Renn's (2004) groundbreaking ecological study with 56 mixed race students included six regionally diverse campuses

\footnotetext{
${ }^{2}$ Identity terminology is contested yet we strive to be inclusive of the expansive ways people might identify within a community, especially in recognition of differences in gender and sexuality. In this article, we follow Salinas' (2020) recommendation to use Latin* as an expansive term when referencing the broader community while at other times using the specific terms that participants used to describe themselves. Latin* considers the identities: Latina, Latino, Latinx, Latine, Latini, Latinu, Latin@, Latin, Latina/o or Latin America (Salinas \& Lozano, 2021). Additionally, we use multiracial and mixed race interchangeably.
} 
Journal Committed to Social Change on Race and Ethnicity | Volume 7, Issue 2 | 2021

of different types, yet all were predominately white (ranging from $12 \%$ to $27 \%$ Students of Color). Harris' $(2017,2019)$ work with multiracial women was centered on students from one RWI. Building on the multiracial microaggressions typology by Johnston and Nadal (2010), Harris (2017) found that multiracial women faced microaggressions that denied their lived experiences as multiracial, made assumptions about being monoracial, or questioned whether they were enough (to fit into monoracial groups). Additionally, Harris (2017) urged for future research at other types of institutions, noting "it remains unknown if these microaggressions would be similar or different in the narratives of multiracial students at Minority-Serving Institutions [MSIs]" (p. 442). More recently, Olivo and Cepeda (2021) echoed the call for more research on multiracial students at MSIs since "we cannot assume that multiracial communities at [RWIs] have the same experiences at MSIs" (p. 19).

Several recent studies have attempted to answer this call for more research with multiracial students at MSIs. Harris and BrckaLorenz (2017) examined Black/white biracial students' engagement patterns at RWls and HBCUs; however, their study did not capture other MSIs like HSIs. Filling a gap on research at Tribal Colleges and Universities (TCUs), Montgomery (2017) examined the politics of identity and difference among multiracial Native American students at a Tribal College. Both of these studies pave ground toward better investigating the unique contexts of MSIs, yet more research is needed with multiracial students at HSIs specifically, especially considering that some HSIs continue to be influenced by the racialization process by continuing to value whiteness, despite being compositionally diverse (Garcia, 2019). Exploring the unique experiences of multiracial students at these institutions is compelling, as HSIs are in 
Journal Committed to Social Change on Race and Ethnicity | Volume 7, Issue 2 | 2021

transition, racially, and actively trying to understand what it means to serve racially minoritized students (Garcia et al., 2019b).

HSIs are some of the most compositionally diverse institutions in the United States (Espinosa et al., 2019). Institutions can apply for the HSI federal designation when they have a Latin* full-time equivalency undergraduate enrollment of $25 \%$ or more; yet the federal government has not established guidelines for effectively "serving" Latin* students, leaving HSI researchers and practitioners to figure it out (Garcia et al., 2019a). Studies examining student experiences at HSIs have emerged, with some observing how students' identities develop at HSIs (i.e. Garcia et al., 2018; Guardia \& Evans, 2008; Onorato \& Musoba, 2015) and others examining sense of belonging at HSIs (i.e. Arbelo-Marrero \& Milacci, 2016). Scholars have also highlighted how faculty pedagogy and curriculum serve students at HSIs (i.e. Alcantar \& Hernandez, 2020; Cuellar \& Johnson-Ahorlu, 2020; Doran, 2019; Garcia, 2016, 2017). An emerging body of scholarship looks specifically at students' racialized experiences at HSIs (i.e. Cuellar \& Johnson-Ahorlu, 2016, 2020; Sanchez, 2019) with several extending this research to Black, Native/Indigenous, and Asian American students (i.e. Abrica et al., 2020; Desai \& Abeita, 2017; Garcia \& Dwyer, 2018; Serrano, 2020). There is still much to be learned, however, about how all Students of Color experience, learn, and develop at HSIs. With no known studies extensively focusing on multiracial student experiences and identities at HSls, it remains unclear to what extent multiracial students, especially those who also identify as Latin*, are reflected in the his context. 
Journal Committed to Social Change on Race and Ethnicity | Volume 7, Issue 2 | 2021

\section{Theoretical Framework}

Two connected frameworks were used as the foundation for this study on multiracial identity at HSIs which come from Kristen Renn's (2004) work on mixed race students in college: an ecological model of student development and the five mixed race student identity patterns. Renn (2004) conceptualized an ecological model of college student development to speak to how individual students construct their racialized identities in response to the various settings they step in and out of. This ecological model consists of identity environments that are created as a function of person, process, context, and time. Of particular relevance to this study was the context component of the model. Renn lays out the context component of the model by describing the interactions between the micro, meso, exo, and macrosystems of higher education that inform multiracial college student development. The microsystem includes curricular and co-curricular structures as well as the various social relationships a student is involved in. The mesosystem is the interactive effects of microsystem processes and is arguably the site of influential college student peer cultures (Renn \& Arnold, 2003). Messages from peers, family, friends, and professors collide in the mesosystem, influencing the ways a multiracial student identifies in any given time and space. Exosystems include policies and practices at the governmental and institutional level that directly or indirectly impact a student's experience and development. Macrosystems are the broader sociohistorical, political, and cultural forces that position students in a particular social location, also shaping their identities (Renn, 2004). 
Journal Committed to Social Change on Race and Ethnicity | Volume 7, Issue 2 | 2021

Additionally, the second framework uses Renn's (2004) five mixed race student identity patterns: monoracial, multiple monoracial, multiracial, extraracial, or situational identity. A monoracial identity pattern is when a multiracial student identifies strongly with only one of their races. A student who demonstrates a multiple monoracial identity pattern avoids adhering to an "either/or" logic and instead, identifies with a "both/and" logic (Renn, 2004, p. 72). For example, a student aligns with the multiple monoracial identity pattern when they identify as both Japanese and white, instead of identifying as either Japanese or white. The multiracial identity pattern is when students identify as multiracial, biracial, or mixed, instead of with their different racial identities separately. The extraracial identity pattern is when students choose to opt out of preexisting racial definitions and categories. A situational identity pattern is when a multiracial student identifies with different patterns depending on the context. All students in Renn's (2004) study who identified as extraracial also demonstrated a situational identity pattern. The ease to which students can shift back and forth in-between identity patterns is largely dependent on the fluidity of the group boundaries in students' micro and mesosystems. Further, it is important to note that these patterns are not mutually exclusive nor linear. Students can, and will, identify with more than one pattern sometime in their college careers and beyond (Renn, 2004).

Despite Renn's (2004) research being conducted at RWls with large sample sizes, her ecological model and patterns of multiracial student identity were nevertheless informative for making sense of how students were identifying themselves in response to environmental contexts. The patterns have also proven useful in more recent studies on multiracial students (e.g., Harper, 2016; Museus et al., 2015, 2016) as 
Journal Committed to Social Change on Race and Ethnicity | Volume 7, Issue 2 | 2021

well as for multiethnic students (Chaudhari \& Pizzolato, 2008). Although this study was not a traditional ecological study nor student identity development study, using these frameworks helped us understand the interactions between multiracial students' identities and their HSI contexts.

\section{Methods}

In order to understand the interactions between the identities of multiracial students and HSI contexts, data from two, four-year HSIs in the Midwest were used. The data are from a larger, multiple case study (Stake, 2006) that examined how students, faculty, and staff make sense of an organizational identity for serving Latin* students at HSIs. The larger project grew out of the need to understand an HSI organizational identity that evolves as the result of changes in the demographic makeup of the institution, with case study methodology being appropriate for describing evolving phenomena (Yin, 2012) such as the evolution of a new organizational identity (Garcia, $2016,2017)$. In this article we accessed student-level data from the two cases to understand how multiracial students' identities were reflected within the broader HSI context, considering their perspective as we aimed to understand how a racialized HSI identity influences students' racialized identities (Garcia, 2019; Garcia \& Dwyer, 2018).

\section{Case Study Site Descriptions}

Both HSIs are compositionally diverse with Students of Color representing between $54 \%-60 \%$ of the student population. The first HSI, Azul City University (ACU; a pseudonym) is a four-year, midsize, public institution classified by Carnegie as a master's college/university. Of the institutions in the sample, ACU has the most extensive offerings of Latin ${ }^{*}$ centered programs and services, including a Latin* cultural 
Journal Committed to Social Change on Race and Ethnicity | Volume 7, Issue 2 | 2021

center. It also has support programs that cater to low-income students and other Students of Color, as well as a center for undocumented students (Garcia, 2019). ACU also has some curricular offerings that allow students to explore their social identities and to develop a social justice orientation (Garcia, 2019). The second HSI, Rosado Private University (RPU; a pseudonym), is a small, private university classified by Carnegie as a master's college/university. It is an urban, comprehensive university that provides a professional, career-focused undergraduate education. The curriculum is career focused and the support and advising that students receive is intended to get them out in four years or less (Garcia, 2019).

ACU and RPU are similar in that they are federally designated as HSIs in the Midwest and have compositionally diverse populations, but are quite different in other contexts, such as curricular and co-curricular offerings (Garcia et al., 2019b). This distinction suggests these institutions might differentially reflect and serve racially minoritized students, which are important contexts that the multiracial literature reviewed above proposes influence the experiences of multiracial students. Students in this study are invariably influenced by their specific institution, making these two cases ideal for exploring questions about how the HSI context influences students' identities.

\section{Data Sources and Sample}

In line with case study methodology, multiple forms of data were collected for the larger study including one-on-one interviews and focus groups with students and educators on campus, observations, and a photo elicitation project with students (Garcia \& Zaragoza, 2020) to understand the "what" and the "how" of the phenomenon (Merriam, 2009; Stake, 2006; Yin, 2009). The core phenomenon we discuss in this 
Journal Committed to Social Change on Race and Ethnicity | Volume 7, Issue 2 | 2021

article is how mixed-race students perceive their own identities and experiences reflected within an institution that is compositionally diverse. Students participated in a one-on-one or a focus group interview, based on their availability. All focus groups included a diverse sample of students by race/ethnicity, sex/gender, year in school, and major, with no groups being exclusive to one identity. For this study, we focus on eight of the 63 student participants from the larger study who identified, either through their interviews or on the demographic form, with more than one race or ethnicity (see table 1). Though there is no consensus on sample size minimums for case studies or qualitative research generally, the multiple forms of data and depth to which participants described nuances of their identities and experiences provided us with confidence that the amount of data was enough for the exploratory nature of this study.

The eight participants identified their race/ethnicity and sex/gender on the demographic form through an open-ended question, so responses varied tremendously (the exact questions were: "How do you identify racially/ethnically?" and "What is your sex or gender identity?"). Collecting data about race and ethnicity through an openended demographic question was a way to operationalize the nuanced meanings of race and ethnicity that students at HSIs hold. What is meant by "race" and "ethnicity" in this study is an intentional shift away from the common practice in higher education research of enumerating race and ethnicity by just one metric (e.g., a demographic survey question). We consider the various meanings of race and ethnicity that participants held about their identities across the open-ended question and within their interviews, which could differ from how race and ethnicity is generally measured in research. We found this complexity useful toward de-essentializing dominant 
Journal Committed to Social Change on Race and Ethnicity | Volume 7, Issue 2 | 2021

understandings of race and ethnicity in higher education research (Johnston-Guerrero, 2017).

Table 1. Participant Demographics

\begin{tabular}{|c|c|c|c|c|c|c|}
\hline Participant & Institution & $\begin{array}{l}\text { Race on } \\
\text { form }^{3}\end{array}$ & $\begin{array}{l}\text { Race in } \\
\text { interview }\end{array}$ & $\begin{array}{c}\text { Sex/ } \\
\text { Gender }^{3}\end{array}$ & Year & Major \\
\hline Amy & RPU & $\begin{array}{l}\text { Black/Native } \\
\text { / Colombian/ } \\
\text { Irish }\end{array}$ & Black & Male & $\begin{array}{l}\text { Sophomor } \\
\text { e }\end{array}$ & $\begin{array}{l}\text { Business } \\
\text { Administration and } \\
\text { Clinical Psychology }\end{array}$ \\
\hline Angie & ACU & Other & $\begin{array}{l}\text { Black/ Puerto } \\
\text { Rican/ Native }\end{array}$ & Female & Junior & $\begin{array}{l}\text { Human Resource } \\
\text { Development }\end{array}$ \\
\hline Bee & ACU & $\begin{array}{l}2 \text { or more } \\
\text { races }\end{array}$ & $\begin{array}{l}\text { Cuban/ Dutch/ } \\
\text { Austrian/ Irish }\end{array}$ & Female & $\begin{array}{l}\text { Master's } \\
\text { Student }\end{array}$ & $\begin{array}{l}\text { Community and } \\
\text { Teacher Leadership }\end{array}$ \\
\hline Bernadette & ACU & $\begin{array}{l}\text { Mexican } \\
\text { Irish } \\
\text { American }\end{array}$ & $\begin{array}{l}\text { Mexican Irish } \\
\text { American }\end{array}$ & Female & $\begin{array}{l}\text { Master's } \\
\text { Student }\end{array}$ & School Counseling \\
\hline Bobby & RPU & Mixed & $\begin{array}{l}\text { Mixed/ Black/ } \\
\text { white }\end{array}$ & Male & Senior & Culinary Arts \\
\hline Juanita & RPU & Hispanic & $\begin{array}{l}\text { Puerto Rican/ } \\
\text { Black }\end{array}$ & Female & Junior & Culinary Arts \\
\hline Marie & RPU & Hispanic & Mexican/ white & Female & Junior & $\begin{array}{l}\text { Business Studies in } \\
\text { Applied Health }\end{array}$ \\
\hline Pablocito & RPU & $\begin{array}{l}\text { Half white/ } \\
\text { Half Filipino }\end{array}$ & Filipino/ white & Female & Senior & Culinary Arts \\
\hline
\end{tabular}

${ }^{3}$ Students were asked to identify their race/ethnicity and sex/gender through an open-ended question on a demographic form and were asked to choose a pseudonym. The information presented here are the exact terms used by participants to identify themselves.

An in-depth, semi-structured protocol for all focus groups and interviews was used, which allowed for direct questioning and emerging ideas as guided by the participants' worldview (Merriam, 2009). Interviews and focus groups were conducted in-person by at least one member of the research team, were audio recorded, and lasted 45-60 minutes. The goal of the interviews was to explore what students think it means to serve minoritized students, and to understand how they perceive their college/university to serve minoritized students through curricular and co-curricular practices. Sample questions included, "In what ways do the curriculum/course offerings include and/or exclude diverse groups?" "In what ways do the co-curricular offerings include and/or exclude diverse groups?" "In what ways do you see yourself represented 
Journal Committed to Social Change on Race and Ethnicity | Volume 7, Issue 2 | 2021

on this campus?" Of note, students made sense of the term, "diversity" in their own ways, although they primarily focused on racial/ethnic diversity and not other forms (e.g., gender, sexual orientation).

\section{Data Analysis}

Audio files were professionally transcribed using Landmark Associates (www.thelai.com) and then verified by at least one member of the research team, including the first and third author of this article. The initial round of data reduction consisted of reading and open-coding eight transcripts of interviews with faculty and staff and four transcripts of interviews with students. We then developed a coding structure inclusive of 73 parent and child codes. The 73 codes were identified at the manifest level, meaning they were based on directly observable information (Boyatzis, 1998). After developing and refining the definitions of each code and following three rounds of inter-rater reliability, we used NVivo 11 to code the full dataset. For this analysis which focuses only on the 8 identified multiracial students, we developed a student only dataset and used data and codes from the larger dataset to help organize and triangulate the data. Of the eight participants in this sample, one participated in an individual interview and the other seven students' data were drawn from their participation in a focus group interview.

Since the unit of analysis for this study was students, we created individual cases in NVivo 11 to represent each student's responses. Guided by Renn's (2004) patterns of multiracial identity, we first examined how each student identified racially/ethnically. The first and second author reviewed cases individually to develop holistic interpretations. Queries were then used to compare cases by preexisting codes in the 
Journal Committed to Social Change on Race and Ethnicity | Volume 7, Issue 2 | 2021

larger dataset. Common themes in student identity patterns were discussed until we reached consensus. We then sought to understand the larger phenomenon (Stake, 2006) of how these identity patterns might relate to the HSI context. At this stage of analysis, we aimed to identify themes at the latent level, or directly underlying the phenomenon (Boyatzis, 1998). As themes emerged, we drew primarily on the theoretical underpinnings of Renn's (2004) ecological model to understand how students were connecting or not connecting their multiracial identities to larger societal and institutional structures and systems.

It is important to note that while students were the unit of analysis for this study, our meaning-making focused on identifying themes at both the individual and organizational level. This means that we were interested in drawing out themes that speak to HSIs as unique institutions within the postsecondary field. Our intent here is not to homogenize HSIs, as they are institutionally diverse (2-year, 4-year, private, public, large, small, etc.); rather, our intent is to intentionally examine aspects of HSIs that may function differently than RWls from a perspective consistent with the literature on multiracial student experiences and identity as well as with the experiences of the participants at their institutions. We also drew on the expansive HSI literature that highlights how faculty, staff, and administrators transform organizational structures to better serve their students (Garcia, 2019; Garcia et al., 2019a, 2019b). Findings are presented by themes while comparing and contrasting these findings to the previous literature centered on multiracial students at RWls where appropriate. 
Journal Committed to Social Change on Race and Ethnicity | Volume 7, Issue 2 | 2021

\section{Positionality of Researchers}

The need to consider the racialized positionality of the researchers is important considering the heavy implications race has on informing research and practices in diverse contexts such as HSIs and in homogenous contexts such as RWls (Milner, 2007). The first and second author identify as multiracial and the third author as Latina. Identifying with the racial meaning making of participants is a form of epistemological validity. All three authors draw on critical frameworks in their research to deconstruct normative understandings of the lived experiences of racially minoritized people and communities. Interpreting data from Communities of Color through critical perspectives is a way to disrupt the white, dominant, racialized systems of knowing that often contributes to the misinterpretation and misrepresentation of the identities and experiences of People of Color.

\section{Findings: Participant Identities in Context}

This study asked two research questions: (a) How do multiracial students at HSIs see their identities reflected or not reflected at their institution? And, (b) how might the HSI context influence these identities? Our analysis came to two main themes toward answering these research questions. First, how students made sense of their multiracial identities was nested within an HSI meso system of diversity and inclusion. Second, the HSI exosystem of Latinidad ${ }^{3}$ was useful in exploring the nuances in participants' multiracial identities as it relates to the HSI context further. Yet, to fully contextualize

\footnotetext{
${ }^{3}$ The term Latinidad is a panethnic term used to describe the culture of those who are from ethno-racially Latin* backgrounds. Latinidad has been criticized as an essentialist and reductionist approach to understanding Latin* experiences as it does not capture the complexities of all those who the term purports to represent. The authors choose to use the term as a recognition that, like the term itself, the $\mathrm{HSI}$ exosystem of Latinidad that we explore in this paper is one participants make sense of in a way that suggests their HSIs reflects Latin* cultures along panethnic, amphorous, and changing lines (CamineroSantangelo, 2007).
} 
Journal Committed to Social Change on Race and Ethnicity | Volume 7, Issue 2 | 2021

students' identities, we provide a brief background of the multiracial identity patterns (Renn, 2004) and then detail how these patterns may be influenced by how students were conceptualizing the meso- and exo-level context of their HSIs.

\section{Background of Multiracial Student Identity Patterns}

Consistent with the pre-existing literature on multiracial identity patterns at RWIs, students presented with either a monoracial, multiple monoracial, multiracial, extraracial or situational identity pattern (Renn, 2004). Which patterns participants presented with are discussed alongside how participants identified their race and ethnicity (e.g., multiracial Latino). The wording used to describe participants is their own, including their sometimes use of the term "Hispanic." The word "Hispanic" derives from the word Hispania or Espanã meaning Spain. It is a panethnic term reflective of western essentialist constructions of race and ethnicity that conflates language with nationality, while including and excluding certain identities based on U.S. racialized policies regarding Latin* people (Salinas, 2020; Salinas \& Lozano, 2019).

All eight participants identified as multiple monoracial through the interview, demographic form, or both. Seven of the eight participants also demonstrated a situational identity across demographic survey and interview. Notably, Amy (all names are self-selected pseudonyms) was the only one who identified as monoracial in the interview and was the only one to identify as monoracially Black. Of the six Latina/o students, all but two of the participants identified as multiracial Latina/o. Juanita and Marie were the only ones to identify as monoracial "Hispanic" on the demographic form, yet they shifted to a multiple monoracial pattern in the interview. The inconsistency between how participants identified on the demographic form and in the interview is a 
Journal Committed to Social Change on Race and Ethnicity | Volume 7, Issue 2 | 2021

manifestation of situational identity and aligns with Renn's (2004) finding that students who identify with the multiple monoracial identity pattern are also likely to exhibit a situational identity. In the present study, situational identity was most often influenced by certain microsystems the student interacted with, which were nestled in (a) the HSI mesosystem of diversity and inclusion; and (b) the HSI exosystem of Latinidad.

\section{Interactions Between Multiracial Identity and HSI Mesosystem of Diversity and Inclusion}

The interactions between microsystems create mesosystems (Renn, 2004). For example, the information a multiracial student receives from their parents (microsystem) about their racial ancestry may interact with the messages they receive from peers at school about how they should racially identify thereby creating a mesosytem, or a field, in which information is interpreted and internalized by the student (Renn, 2004). In this finding, the interactions between individual students' dominant racial identity influences (physical markers and cultural knowledge; Renn, 2004) and the micro- and mesosystems within the HSI context are discussed.

Reflecting the compositional diversity at HSIs, which attract large numbers of racially minoritized students (Hurtado \& Ruiz Alvarez, 2015), participants often perceived their multiracial identity to be supported by the general culture of "diversity" and "inclusivity" of their institutions. This supportive culture was substantiated by participants comparing their current experiences at HSIs to their previous experiences at RWIs. Given that six of eight participants had been enrolled at RWls as undergraduate or graduate students prior to being at their HSIs, being able to compare and contrast their experiences at an HSI with an RWI helped provide depth to their 
Journal Committed to Social Change on Race and Ethnicity | Volume 7, Issue 2 | 2021

understanding of their multiraciality as situated within the specific context of an HSI. The most illustrative examples of how exactly students were conceptualizing the HSI mesosystem of diversity and inclusion was through the use of physical markers and cultural knowledge as influences on their multiracial identities.

Mesosystem Interactions with Physical Markers. Participants tended to conceptualize the meaning of their multiraciality through racial ascription, or how others categorize them racially based off of physical markers. Angie, for instance, who identified as "other" on the demographic form (an extraracial identity pattern), described herself as Black/Puerto Rican/Native (a multiple monoracial identity pattern) in the interview saying, "What it [being Black/Puerto Rican/Native] means to me is that I always get mistaken for something else." Likewise, Pablocito said, "I'm always mistaken for being Hispanic everywhere I go. It's just, I'm always mistaken for something that I'm not." Despite these examples clearly signaling the multiracial microaggression of mistaken identities (see Johnston \& Nadal, 2010), participants generally did not describe feeling racially discriminated against at their institutions.

The HSI mesosystem of diversity and inclusion provided context for multiracial students to not interpret racial ascription as microaggressive. For instance, although Angie spoke of her experiences throughout her life with people ascribing a race onto her based on physical markers, she described feeling supported by the racial diversity in the student population at her HSI stating,

Here there's a lotta diversity. There are a lotta students here from different backgrounds and nobody seems to care-which is great. There's no barrier because you may be this and I may be that [...]. Everybody here's been a pleasure. I really love that about ACU. I'm a quarter [Puerto Rican], but I'm just kind of in the "other" box, but I still love coming to ACU. [...] In my opinion it's a genuine experience here. Period. 
Journal Committed to Social Change on Race and Ethnicity | Volume 7, Issue 2 | 2021

Similarly, Pablocito shared,

You just have a mix of everybody. It's something different to see. It's diverse. We should always have a population that's diverse, 'cause you always have a lot to learn about other people in other cultures. If I stick with one place, one type of race or culture, and one type of school, it's harder to learn about other cultures.

Echoing these sentiments, Juanita, who identified as Hispanic (monoracial) on the demographic form, described herself as Puerto Rican/Black (multiple monoracial) in the interview. In the interview she discussed how she identified as Puerto Rican growing up because she attended RWls her whole life, sharing that her peers ascribed her as monoracially Puerto Rican. At her HSI, however, Juanita seemed to feel more comfortable identifying in a multiple monoracial manner through statements she made about how RPU is more racially diverse than the RWI she previously attended:

I went to this one private [high] school, and it was just full of Caucasian people. Me being Hispanic and Black, and them usually having straight hair, they would be like, "Oh, how do you get your hair like that? Is it fake?" [...] Coming to RPU and seeing other people that are Hispanic and any other race, and they have curly hair, and it's just like, oh, I don't need to be so uncomfortable with having curly hair anymore, because everyone else has it here, too.

As a multiracial woman, Juanita seems aware that her physical appearance may perpetuate monoracial assumptions about her identity. Juanita's experience at her previous predominately white schools mirrors the findings of a previous study done at a RWI that found that multiracial women use physical indicators, such as hair, to counter monoracial stereotypes (Harris, 2017). Juxtaposing this experience to her experience at an $\mathrm{HSI}$, Juanita did not describe her physical appearance to be a source of anxiety, but rather, as a source of self-acceptance. Juanita described this sense of acceptance and inclusivity as something characteristic of the institution as a whole. 
Journal Committed to Social Change on Race and Ethnicity | Volume 7, Issue 2 | 2021

Mesosystem Interactions with Cultural Knowledge. Cultural knowledge is important to the way multiracial students construct their racial identities (Renn, 2004). Students who identify in the multiple monoracial pattern often make sense of their identity through possessing or lacking cultural knowledge pertaining to their racial/cultural backgrounds (Renn, 2004). Most students in the sample, particularly those who were also Latina/o $(n=6)$, made sense of their multiple monoracial identity through cultural knowledge of speaking Spanish. For instance, when asked what it means for her to be Black/Puerto Rican/Native, Angie shared,

There's Puerto Ricans here and they're like, "Oh, you're Puerto Rican?" "Yes, I am." "Oh, cool. You speak Spanish?" "Nope." Well that's always been a stopping point for me. I don't think there's anything that [ACU] can do further [to support my identity]. They're doing a good job. Like if I look around my classrooms there's many minorities and a few people are as tan as me, but I have bits and pieces of me here. I see Hispanic people here and that's me, that's not me, that's a part of me, but there's differences and such. There are people who will just group up and speak Spanish all day. I can't speak it, but I understand it.

Similarly, when Marie was prompted to consider what it means to her to identify as Mexican and white said, "I don't speak Spanish fluently. I understand a lot of it and I guess you could say I speak Spanglish just because my parents primarily speak English." Bee further explained her relationship to her cultures, sharing, "I don't really know anything about my culture. I don't speak Spanish, unfortunately." Although there was a sense of internalizing threats to her racial authenticity as being part Latina because of her inability to speak Spanish, Bee described feeling welcomed at her HSI, saying,

I never really identified with one specific ethnicity or group here [at ACU]. ACU as a whole, I feel, it's just welcoming of every culture, which I guess is the culture here in and of itself [...]. There's many different cultures here, but also just the general culture of it is the fact that it's just so open. I feel like everyone is included. No one is left out. 
Journal Committed to Social Change on Race and Ethnicity | Volume 7, Issue 2 | 2021

Multiple microsystems, such as peer interactions seemed to contribute to students constructing an HSI mesosystem defined by diversity and inclusion. The next theme complicates this further by explaining how the exosystem of Latindad, and connections to whiteness, multiraciality, and (anti)Blackness, influences the way multiracial students made sense of their racial identities within their HSIs.

\section{Interactions between Multiracial Identity and the Exosystem of Latinidad}

Latinidad is a contested term with much debate about the extent to which is privileges whiteness and excludes Blackness (Dache et al., 2019). Though theorizing these constructs is outside the scope of this study, we found patterns related to students' multiracial identity interactions with their HSI context in relation to their connection to a larger exosystem of Latinidad, which was ultimately related to students' proximity to whiteness and (anti)Blackness.

Proximity to Whiteness. For the six students in the sample (out of eight) who identified as mixed with white, the degree to which they identified with their whiteness may have influenced the way they perceived their HSIs. Bobby and Pablocito, the only two students in the sample who were not multiracial Latina/o, did not seem to identify strongly with their racially minoritized identities. Bobby identified as mixed on the demographic form (a multiracial pattern), but in the interview had a complex conceptualization of his identity that seemed to stem from his family microsystem. Bobby identified with a multiple monoracial pattern (Black/white), while also identifying multiracially (mixed) and extraracially (human), saying,

Growing up, we always had to check those boxes saying what your race was, and it never had "other" or "mixed." There was only Black, white, Spanish, whatever. I dunno, I identify as mixed, even though I'm Black and white, because 
Journal Committed to Social Change on Race and Ethnicity | Volume 7, Issue 2 | 2021

it doesn't really matter. My dad was like, "on all your job applications, if it says 'race,' and it says 'other,' always put 'human,' because it doesn't really matter" and that's gotten me a couple jobs.

Bobby's sense making of his multiracial identity speaks to the tendency for some biracial people who can pass as monoracially white (through phenotypes/behavior) to minimize their racially minoritized background and emphasize their dominate white heritage in order to avoid systemic inequities that come with being a Person of Color (Harris, 2017).

Further, Pablocito, when asked what it meant for her to be Filipino/white only discussed her racial identity in relation to being exposed to people from Latin* backgrounds growing up. For Pablocito, her proximity to whiteness (through being biracially white along with the perceived phenotypes/behavior that comes with this) could have facilitated her passive acceptance of the dominant white identity, while the HSI context may have prompted her to make sense of her multiraciality in proximity to Latinidad. Although the compositional diversity at HSIs presents the potential for all multiracial students to safely engage in an exploration of their multiracial identities, for Bobby and Pablocito, a lack of microsystem on campus that specifically supported their Black and Filipino identities, respectively, might have impeded their readiness to claim these identities more deeply (Renn, 2004).

Multiraciality and Latinidad. Like Bobby and Pablocito, Bee, Marie, and Bernadette are also mixed with white ancestry; however, Bee, Marie, and Bernadette are also multiracial Latinas. Being both Latina and white might contribute to how Bee, Marie, and Bernadette were able to identify with both a white and a Latin* culture. They were more able than Pablocito and Bobby to situate their multiracial identities within 
Journal Committed to Social Change on Race and Ethnicity | Volume 7, Issue 2 | 2021

microsystems on campus that not only spoke to their Latina identities, but to larger issues affecting Latin* populations within an exosystem of Latinidad.

For example, Bee, when asked what it means for her institution to be Latin*serving said, "there's a lot of diverse clubs and sororities and fraternities that are for Hispanics, because those types of groups are really important to them." Although Bee is multiracial Latina, she did not seem to identify with social groups that are dedicated specifically to Latin* people. This absence could be because she later stated she identifies as "...mostly Caucasian or European American." Bee further described feeling welcomed by the mesosystem of the diverse campus culture, saying, "even though you walk through [the cafeteria] and you see different cultures cliquing up, even though there's separate groups, we're still one," while also speculating that "maybe if [she was] fully Caucasian" she might feel less welcomed.

Another example is Marie, whose potential insecurities about speaking Spanglish as a marker of her Latina identity was subdued by the mesosystem of her health business major. Marie discussed how her department offered a bilingual SpanishEnglish course that was designed to help students translate medical terminology to Spanish; a course where Marie can possibly find strength in speaking Spanglish in refining and transferring this skill set into her future career.

Likewise, Bernadette talked about the tensions she felt in the past about not being fluent in Spanish, yet discussed a service available on her campus that supports peer-to-peer language learning. The microsystem of peer interactions combined with the microsystem of campus services led to a mesosystem that was conducive to 
Journal Committed to Social Change on Race and Ethnicity | Volume 7, Issue 2 | 2021

Bernadette strengthening her Latina identity through acquiring cultural knowledge in the form of language. This mesosystem was influenced by an exosystem of Latinidad.

Proximity to Latinidad. Angie and Juanita are the only two students in the sample who do not identify as mixed with white. Because of the macrosystem of race relations in the United States contributing to whiteness being the default, dominant race, students who are mixed with two or more minoritized groups are more likely to readily identify with all/one of their minoritized identities than students who are multiracial white (Renn, 2004).

In understanding how she sees her multiracial identity reflected at ACU, Angie responded with, "Racially, I'm represented in increments and pieces and not even to that degree. There's nothing here for Natives. We're the minority of minority. I take being Native very proudly. I'm actually very close to my grandparents who are Native. It's something that I take to heart." Though Angie did not experience support from her institution in connecting to microsystems that reflect her Native identity, her multiple monoracial pattern of being part Latina allowed her to (re)connect to her Puerto Rican heritage:

My mother's half Puerto Rican. Do I know anything about Puerto Rico? Absolutely not, but I have family who speak only Spanish. [...] l've asked random people questions in my classes because I don't particularly speak fluent Spanish. In the Latin communities there are so many differences. A lot of people like to sum [Latin*] together. They're differences between Puerto Ricans and Cubans, different dialects. It's always interesting that you can actually talk to people from different backgrounds at ACU and kind of see like, "What's different from you, from me, from this, that, and the other?" People are really friendly with answering all my questions.

Because Angie identifies as part Puerto Rican, she was able to make sense of her multiracial identity through the interactions between her various microsystems (family, 
Journal Committed to Social Change on Race and Ethnicity | Volume 7, Issue 2 | 2021

peers interactions, classes) to enhancing her knowledge about Spanish and cultural factors related to her identifying as Latina, given the exosystem of Latinidad. Angie was able to nurture her Puerto Rican identity, while also maintaining her multiple monoracial identity as Native American.

Unlike Angie whose Native identity seemed to be the most salient, Juanita's Puerto Rican identity seemed to be of particular salience. Juanita identified as Black and Puerto Rican (multiple monoracial) in the interview; However, she mostly discussed the influence her Puerto Rican upbringing had on her educational trajectory and not being Black throughout the interview. Juanita shared how being raised by a Puerto Rican grandmother instilled a love for cooking in her that led to her decision to pursue a culinary arts degree at RPU. When making sense of how she understands RPU to be Latin*-serving, Juanita's views were congruent with the purported mission of HSIs:

Coming from just a Puerto Rican household, or just being Latina in general, people generally think every Hispanic drops out of high school because they either get pregnant or they just don't wanna go above their careers. [...] I just think that knowing that this is a Latina/Latino inspired school is cool, cuz it's just like you can show people, yeah, the norm is, oh, Hispanic people drop outta school and have babies, but you can show people, no, not everyone is gonna do that. Everyone has their own future ahead of them. Sometimes you wanna break the cycle and show people that you can be successful being that way.

For Juanita, her family and peer microsystems and her macrolevel perceptions provided congruency between her identity and the Latinidad exosystem of the institution.

Conversely, Amy, was the participant who experienced the most incongruency between the $\mathrm{HSI}$ context and his multiracial identity. Although Amy described himself as multiple monoracial on the survey, he identified as monoracially Black in the interview. When asked how he sees his multiracial identity reflected in the institution, Amy said that in most of his classes he feels like he's "the token black guy in a sea of white." Amy 
Journal Committed to Social Change on Race and Ethnicity | Volume 7, Issue 2 | 2021

choosing to identify as monoracially Black might signal something about the $\mathrm{HSI}$ context, where according to Amy, racial diversity was present in the student body, yet there remained a lack of Black students. In Amy's situation, the anti-Blackness inherent in macro structures in the United States, might lead him to identifying as monoracially Black as he might not see distancing himself from Blackness as feasible (Brunsma \& Rockquemore, 2002), even within a context as compositionally diverse as an HSI. AntiBlackness is a ubiquitous ideology that maintains the existence of whiteness only in contrast to Blackness as the lesser (Dache et al., 2019).

A function of anti-Blackness is tokenization, where a Black person, even a mixed Black person, is biologically essentialized and valued insofar as their white appeasing representation of their race (Beatty et al., 2020). Amy feeling like the "the token black guy" is an example of anti-Blackness functioning at Amy's HSI. In addition to tokenization, Amy described having to "hunt [racially diverse] faculty down" and repeatedly made statements about how there was a lack of a physical space on campus that reflected his multiple racial identities. In this way, the mesosystems in the HSI sent incongruent messages about his ability to identify as multiple monoracial and possibly guided him to identify with only one of his racial identities (Black being the one with the strongest systemic pull). However, students who experience incongruity develop strategies to manage the conflicting messages they receive from their institutional contexts when attempting to make sense of their multiple monoracial identities (Renn, 2004).

Amy quite possibly felt pressured by the campus mesosystem of diversity and inclusion to represent diversity in a narrow way. Amy, as someone who identifies 
Journal Committed to Social Change on Race and Ethnicity | Volume 7, Issue 2 | 2021

situationally as multiple monoracial, is not only subjected to the influence of the environment on his development but has agency to influence the environment in return (Renn, 2004). This was seen through Amy's multiple recommendations on how RPU can move toward being more culturally responsive and racially diverse. Amy's criticality of RPU's lack of Black students and faculty and support structures for minoritized students, may be related to his sociopolitical position on the distal end of whiteness and Latinidad.

\section{Discussion and Implications}

Across a wide array of identity patterns, including situational identities, the multiracial student sample in this study generally felt supported by the ecological systems present at their HSIs. Renn's (2004) identity patterns and contexts were apparent in this study. However, important differences between Renn's sample of RWls and the two HSIs in this study are important to note. Renn (2004) identified specific mechanisms that multiracial students at RWls use to make sense of their multiracial identities. A contribution of this study to the literature on multiracial college students is the closer examination of the systems multiracial students at HSIs navigate to explore their multiracial identities and the revelation that the institutional factors that most influence multiracial students at RWIs differs from those at HSIs.

Multiracial students at RWls tend to need specific microsystems (e.g., clubs, services, spaces) to explore and validate their multiracial identities, often through gaining cultural knowledge (Renn, 2004). In this study, cultural knowledge was also important, yet at HSIs, cultural knowledge took on a different role. Multiracial Latina/o students in this sample, despite not having access to certain cultural knowledge (e.g., 
Journal Committed to Social Change on Race and Ethnicity | Volume 7, Issue 2 | 2021

not speaking Spanish), did not feel excluded from the institution. Rather, they saw themselves reflected at their institutions via the mesosystem's commitment to diversity and inclusion, and the exosystem's connection to Latinidad broadly. Contributing to this finding is the implication that HSIs that are more Latinidad-centered (e.g., Latin* students being around culturally similar peers), contributes to the salience of a Latin* identity (Garcia et al., 2018), and as this study shows, even for those who are multiracial Latina/o.

Feelings of exclusion and marginalization are common themes among multiracial students experiencing microaggressions at RWls (Harris, 2017; Kellogg \& Liddell, 2012; Museus et al., 2015, 2016) and non-Latin* Students of Color at HSIs (Abrica et al., 2020; Desai \& Abeita, 2017; Serrano, 2020). The findings in this study suggest, however, that this was not the case for multiracial students at the HSIs in this sample, especially when students compared their HSI experiences with their previous experiences at RWls. For instance, Juanita experienced multiracial microaggressions growing up in predominantly white educational settings with others imposing their racially stereotypical perceptions of her physical appearance onto her identity. Yet, the $\mathrm{HSI}$ context seemed to provide her with racially congruent messages for the first time, where she was able to see herself reflected within the HSI context given shared cultural values and similar physical appearance to many of the monoracial Latin* students on campus. This finding also aligns with Cuellar and Johnson-Ahorlu's (2020) findings about students at one emerging HSI who talked about how faculty at their community college validated them, thus disrupting the deficit narratives they heard about their academic and linguistic abilities prior to college. 
Journal Committed to Social Change on Race and Ethnicity | Volume 7, Issue 2 | 2021

Additionally, HSIs can be thought of as "institutions with special missions [... that] attract and support particular types of student bodies, acting as ecological niches that are especially favorable to students whose attitudes and characteristics are congruent with institutional philosophies" (Renn, 2004, p. 46). HSIs are organizations that are dedicated to increasing access to higher education for minoritized students, particularly for Latin* populations (Santiago, 2006). Even without specific microsystems that were tailored to multiracial students, the whole campus, in many ways, reflected their identities as diverse racial beings. This seems to be a key distinction between multiracial students' experiences at RWls and HSls that warrants attention in future research, particularly whether it is just the compositional diversity making the difference or if there is something particular about the Latin*-serving organizational identity (Garcia, 2019).

Considering how extensive physical markers and cultural knowledge inform racial/ethnic identity (Renn, 2004) is one part of understanding how HSls can support multiracial students. The second is understanding the ways in which the HSI environment influences how multiracial students differentially construct their racial/ethnic identities. An example of this in the data is the cases of Juanita and Amy. Although Juanita and Amy both identified as Latina/o and Black and attend the same $\mathrm{HSI}$, Juanita was more inclined to identify in a monoracial Latina manner and Amy a monoracial Black manner. These two students experienced their institutions in very different ways, with Juanita feeling she was supported and Amy feeling he was not. This distinction points to the importance of HSIs, as racialized institutions, must exercise intentionality in serving Afro/Latin* and all multiracial students in ways that do not treat 
Journal Committed to Social Change on Race and Ethnicity | Volume 7, Issue 2 | 2021

their identities as mutually exclusive (Dache et al., 2019; Esmieu \& Terrazas, 2017), especially given Garcia and Dwyer's (2018) finding that Black students at HSIs resent the HSI designation and were often dissenting of the minority-serving connotation. Similarly, Serrano (2020) revealed the frustration of Black students who said HSI institutional diversity claims are false narratives for Black students who find themselves in the minority at HSIs.

The findings from this study also highlight important implications for practice, namely, that RWls might be able to learn from HSls about how to develop supportive environments for multiracial students (even without necessarily trying). Taking an ecological approach to understanding campus contexts is important to recognizing the various microsystems multiracial students may be interacting with, yet more importantly, the fact that the larger culture in the mesosystems and exosystems of HSIs seemed to validate multiracial students. Literature suggests the importance of multiracial student organizations for belonging and identity development (Malaney \& Danowski, 2015), yet at these HSls, there was not a critical mass of students identifying as multiracial to create a separate reference group (see Renn, 2000, for a discussion of critical mass and its role in the creation of mixed-race spaces). While the importance of race-specific groups and spaces cannot be underscored, the important point to note is that multiracial students can feel validated within a larger culture of diversity and inclusion that is also compositionally diverse. RWls and MSIs should strive to create various microsystems, whether that be classes, groups, workshops, etc. where students can explore their multiple heritages_like Angie and Bernadette, who took advantage of microsystems as opportunities to explore/strengthen their Latina identity, without disregarding their 
Journal Committed to Social Change on Race and Ethnicity | Volume 7, Issue 2 | 2021

multiple monoracial identities. Overall, by exploring the identities and experiences of multiracial students at HSIs, this study opens the door to further investigations of this often-overlooked student population within diverse institutional contexts.

\section{Study Limitations}

Despite the importance of this study and its unique contribution to the literature as one of the first to explicitly examine multiracial identities within the HSI context, there are limitations that must be acknowledged in hopes that they also lead to additional areas for future research. First, this study was pulled from a larger study focused on HSI organizational identity and included all eight of the 63 participants from that study who identified with more than one race. These students participated in interviews that consisted of anywhere between one to six students from various racial and other identity backgrounds, with one participant (Bernadette) participating in an individual interview instead of a focus group. Though the sample was sufficient for the "goodness" of the exploratory nature of this qualitative study (Arminio \& Hultgren, 2002), it is difficult to ascertain how the findings would have differed if there had been a more representative sample of non-Latin* multiracial students across both institutions. Further, the two HSIs in this study varied in institutional type and resources offered to minoritized students which invariably influenced the findings. Another limitation is that this sample included two graduate students, whose previous experiences at RWIs during their undergraduate careers may have informed their identity development more than their current experiences at HSIs. Additionally, their maturity level and ability to articulate their perceptions of the HSI organization may also have been greater than other students given their extended time and exposure to higher education. 
Journal Committed to Social Change on Race and Ethnicity | Volume 7, Issue 2 | 2021

\section{Recommendations for Future Research}

Future research could address the limitations identified above in several ways.

First, future studies should use more purposeful investigation and sampling of

multiracial students with a variety of heritage group combinations and claimed identities.

Second, research should investigate how students' multiple identities (e.g., class,

gender, faith) influence their experiences and interact with the HSI context. Third, studies should compare and contrast multiracial student identity development at various types of MSIs. A more specific cross-case analysis could also further an understanding of the unique institutional contexts that influence the experiences of multiracial students at HSIs and could shed light on how student racial identity is influenced by organizational racial identity, and vice-versa.

Important to note is that this study differs from Renn's (2004) not only in the institutional type, but in terms of the sociohistorical context. The ecological model acknowledges the importance of the time either as its own contextual system (i.e. chronosystem) or captured within the macrosystem and changing social forces. Given that Renn's (2004) data collection ranged between 1996-2002 across three phases, much can be said about the sociohistorical changes in relation to multiracial identity over the past 20 years, given the prominence of former President Barack Obama's biracial Black (and arguably situational) identity and that many traditionally aged students have always known the ability to "check all that apply" after changes to the 2000 U.S. Census (Johnston-Guerrero \& Renn, 2016). More research on potential trends across time might better capture and distinguish between contextual influences 
Journal Committed to Social Change on Race and Ethnicity | Volume 7, Issue 2 | 2021

and sociohistorical changes in how these HSls seem to be environments that are more reflective of multiracial student identities than from past studies at RWIs (Renn, 2004).

Time across the lifespan is also important to consider further. Future research should take longitudinal approaches to identity development at MSIs, which could also better capture the influence of transferring institutions or attending different types of institutions at various levels of education. This teasing out of student development and awareness over time and across different institutions might also further understanding of racial identity development as an indicator of serving, as suggested by Garcia et al. (2019b).

\section{Conclusion}

The findings from this study suggest that multiracial students at HSls feel they are reflected in the mesosystem of diversity and inclusion and the exosystem of Latinidad at their HSls, which is distinct from research at RWls that suggests multiracial students do not see themselves reflected by the overall diversity of RWIs. Yet like RWls, some multiracial students in our study demonstrate an awareness of the way anti-Blackness functions at their institution. This was represented by the relationship between students' understandings of their racialized selves and their proximity to the exosystem of Latinidad at their HSIs.

This study provides a foundation for examining and developing an understanding of how best to serve multiracial students at MSIs. It is especially important to understand mixed raced students' perceptions of their identities and how they find support within their institutions because mixed race students represent a demographic shift toward diversity in the student population across institutional type. All institutions of 
Journal Committed to Social Change on Race and Ethnicity | Volume 7, Issue 2 | 2021

higher education will be increasingly pressured to confront the monoracial ideologies

they perpetuate in policies and practices. For an institution, such as an $\mathrm{HSI}$, to become

more compositionally diverse does not mean that it becomes less monoracist.

Multiracial students may find that their needs are silenced by institutional definitions of

race that is strictly dichotomous and mutually exclusive categorically (Malaney \&

Danowski, 2015). This article contributes to a more informed understanding of how

multiracial students see their identities reflected at their HSIs, which can help to shape

policies and practices that better serve these students.

\section{References}

Abrica, E. J., García-Louis, C., \& Gallaway, C. D. J. (2020). Antiblackness in the Hispanic-serving community college (HSCC) context: Black male collegiate experiences through the lens of settler colonial logics. Race Ethnicity and Education 23(1), 55-73. https://doi.org/10.1080/13613324.2019.1631781

Alcantar, C. M., \& Hernandez, E. (2020). "Here the professors are your guide, tus guías": Latina/o student validating experiences with faculty at a Hispanic-Serving community college. Journal of Hispanic Higher Education, 19(1), 3-18. https://doi.org/10.1177/1538192718766234

Arbelo-Marrero, F. \& Milacci, F. (2016). A phenomenological investigation of the academic persistence of undergraduate Hispanic nontraditional students at Hispanic Serving Institutions. Journal of Hispanic Higher Education, 15(1), 22-40. https://doi.org/10.1177/1538192715584192

Arminio, J. L., \& Hultgren, F. H. (2002). Breaking out from the shadow: The question of criteria in qualitative research. Journal of College Student Development, 43, 446460.

Beatty, C. C., Tevis, T., Acker, L., Blockett, R., \& Parker, E. (2020). Addressing antiBlack racism in higher education: Love letters to Blackness and recommendations to those who say they love us. JCSCORE, 6(1), 6-27. https://doi.org/10.15763/issn.2642-2387.2020.6.1.6-27

Boyatzis, R. E. (1998). Transforming qualitative information: Thematic analysis and code development. SAGE.

Brunsma, D. L., \& Rockquemore, K. A. (2002). What does "Black" mean? Exploring the epistemological stranglehold of racial categorization. Critical Sociology, 28(1-2), 101-121. https://doi.org/10.1177\%2F08969205020280010801

Caminero-Santagelo, M. (2007). On Latinidad: US Latino literature and the construction of ethnicity. University of Florida Press.

Chang, A. (2014). Identity production in figured worlds: How some multiracial students become racial atravesados/as. The Urban Review, 46(1), 25-46. https://doi.org/10.1007/S11256-013-0247-4 
Journal Committed to Social Change on Race and Ethnicity | Volume 7, Issue 2 | 2021

Chaudhari, P., \& Pizzolato, J. E. (2008). Understanding the epistemology of ethnic identity development in multiethnic college students. Journal of College Student Development, 49(5), 443-458. https://doi.org/10.1353/csd.0.0028

Cuellar, M. (2019). Creating Hispanic-Serving Institutions (HSIs) and emerging HSIs: Latina/o college choice at 4-year institutions. American Journal of Education, 125(2), 231-258. https://doi.org/10.1086/701250

Cuellar, M., \& Johnson-Ahorlu, R.N. (2016). Examining the complexity of the campus racial climate at a Hispanic serving community college. Community College Review, 44(2), 135-152. https://doi.org/10.1177/0091552116632584

Cuellar, M. G., \& Johnson-Ahorlu, R. N. (2020). Racialized experiences off and on campus: Contextualizing Latina/o students' perceptions of climate at an emerging Hispanic-Serving Institution (HSI). Urban Education.

Dache, A., Haywood, J. M., \& Mislán, C. (2019). A badge of honor not shame: An AfroLatina theory of Black-imiento for US Higher Education Research. The Journal of Negro Education, 88(2), 130-145. https://doi.org/10.7709/jnegroeducation.88.2.0130

Daniel, G. R., Kina, L., Dariotis, W. M., \& Fojas, C. (2014). Emerging paradigms in critical mixed race studies. Journal of Critical Mixed Race Studies, 1(1), 6-65. https://doi.org/10.5070/C811013868

Desai, S. R., \& Abeita, A. (2017). Institutional microaggressions at a Hispanic Serving Institution: A Diné (Navajo) woman utilizing tribal critical race theory through student activism. Equity \& Excellence in Education, 50(3), 275-289. https://doi.org/10.1080/10665684.2017.1336498

Doran, E. (2019). Developmental instructors in the contact zone: Perspectives from Hispanic-serving community colleges. In I. Baca, Y. I. Hinojosa, \& S. Wolff Murphy (Eds.), Bordered writers: Latinx identities and literacy practices at Hispanic-Serving Institutions (p. 37-51). State University of New York.

Esmieu, P. \& Terrazas, M. (2017). Are you serving all of us? Afro-Latino/as and Hispanic Serving Institutions. In M. Gasman, A.C. Samayoa, W.C. Borland, \& P. Esmieu (Eds.), Educational challenges at Minority Serving Institutions (pp. 140153). Routledge.

Espinosa, L. L., Turk, J. M., Taylor, M., \& Chessman, H. M. (2019). Race and ethnicity in higher education: $A$ status report. Washington, DC: American Council on Education.

Garcia, G. A. (2016). Complicating a Latina/o-serving Identity at a Hispanic Serving Institution. The Review of Higher Education, 4O(1), 117-143. https://doi.org/10.1353/rhe.2016.0040

Garcia, G. A. (2017). Defined by outcomes or culture? Constructing an organizational identity for Hispanic-Serving Institutions. American Education Research Journal, 54(1S), 111S-134S. https://doi.org/10.3102/0002831216669779

Garcia, G. A. (2019). Becoming Hispanic-Serving Institutions: Opportunities for colleges \& universities. Johns Hopkins University.

Garcia, G. A., \& Dwyer, B. (2018). Exploring college students' identification with an organizational identity for serving Latinx students at a Hispanic Serving Institution (HSI) and emerging HSI. American Journal of Education, 124(2), 191-215. https://doi.org/10.1086/695609 
Journal Committed to Social Change on Race and Ethnicity | Volume 7, Issue 2 | 2021

Garcia, G. A., Núñez, A.-M., Sansone, V. A. (2019a). Toward a multidimensional conceptual framework for understanding "servingness" in Hispanic-Serving Institutions (HSIs): A synthesis of the research. Review of Educational Research, 89(5), 745-784. https://doi.org/10.3102/0034654319864591

Garcia, G. A., Patrón, O. E., Ramirez, J. J., \& Hudson, L. T. (2018). Identity salience for Latino male collegians at Hispanic Serving Institutions (HSls), emerging HSIs, and non-HSIs. Journal of Hispanic Higher Education, 17(3), 171-186. https://doi.org/10.1177/1538192716661907

Garcia, G. A., Ramirez, J. J., Patrón, O. E., \& Cristobal, N. L. (2019b). Constructing an HSI organizational identity at three Hispanic-Serving Institutions in the Midwest: Ideal vs. current identity. The Journal of Higher Education. https://doi.org/10.1080/00221546.2018.1522198

Garcia, G. A. \& Zaragoza, M. (2020). Students' perceptions of diversity at two HispanicServing Institutions through pictures: A focus on structures for serving. Association of Mexican American Educators Journal, 14(3), 10-29. https://doi.org/10.24974/amae.14.3.388

Guardia, J. R. \& Evans, N. J. (2008). Factors influencing the ethnic identity development of Latino fraternity members at a Hispanic serving institution. Journal of College Student Development, 49(3), 163-181. https://doi.org/10.1353/csd.0.0011

Harper, C. E. (2016). Pre-college and college predictors of longitudinal changes in multiracial college students' self-reported race. Race Ethnicity and Education, 19(5), 927-949. https://doi.org/10.1080/13613324.2014.911161

Harris, J. C. (2016). Toward a critical multiracial theory in education. International Journal of Qualitative Studies in Education, 29(6), 795-813. https://doi.org/10.1080/09518398.2016.1162870

Harris, J. C. (2017). Multiracial college students' experiences with multiracial microaggressions. Race Ethnicity and Education, 20(4), 429-445. https://doi.org/10.1080/13613324.2016.1248836

Harris, J. C. (2019). Whiteness as structuring property: Multiracial women students' social interactions at a Historically White Institution. The Review of Higher Education, 42(3), 1023-1050. https://doi.org/10.1080/13613324.2016.1248836

Harris, J. C. \& BrckaLorenz, A. (2017). Black, White, and Biracial students' engagement at differing institutional types. Journal of College Student Development, 58(5), 783-789. https://doi.org/10.1353/csd.2017.0061

Hurtado, S., \& Ruiz Alvarado, A. (2015). Realizing the potential of Hispanic-Serving Institutions. In A.-M. Núñez, S. Hurtado, \& E. Calderón Galdeano (Eds.), Hispanic-Serving Institutions: Advancing research and transformative practice (pp. 25-46). Routledge.

Johnston, M. P., \& Nadal, K. L. (2010). Multiracial microaggressions: Exposing monoracism in everyday life and clinical practice. In D. W. Sue (Ed.), Microaggressions and Marginality: Manifestation, Dynamics, and Impact (pp. 123-144). John Wiley \& Sons.

Johnston-Guerrero, M. P. (2017). The (mis)uses of race in research on college students: A systematic review. Journal Committed to Social Change on Race and Ethnicity, 3(1), 5-41. https://doi.org/10.15763/issn.2642-2387.2017.3.1.5-41 
Journal Committed to Social Change on Race and Ethnicity | Volume 7, Issue 2 | 2021

Johnston-Guerrero, M. P., \& Renn, K. A. (2016). Multiracial Americans in college. In K. O. Korgen (Ed.), Race policy and Multiracial Americans (pp. 139-154). University of Chicago. https://doi.org/10.1332/policypress/9781447316459.003.0009

Johnston-Guerrero, M. P., Tran, V. T., \& Combs, L. (2020). Multiracial Identities and Monoracism: Examining the Influence of Oppression. Journal of College Student Development, 61(1), 18-33. http://doi.org/10.1353/csd.2020.0001

Johnston-Guerrero, M. P., \& Wijeyesinghe, C. L. (Eds.). (2021). Multiracial experiences in higher education: Contesting knowledge, honoring voice, and innovating practice. Stylus.

Jones, N., Marks, R., Ramirez, R. \& Ríos-Vargas, M. (2021). Improved race and ethnicity measures reveal U.S. population is much more multiracial. U.S. Census Bureau. https://https://www.census.gov/library/stories/2021/08/improved-raceethnicity-measures-reveal-united-states-population-much-more-multiracial.html

Kellogg, A. H., \& Liddell, D. L. (2012). "Not half but double": Exploring critical incidents in the racial identity of multiracial college students. Journal of College Student Development, 53(4), 524-541. https://doi.org/10.1353/csd.2012.0054

Malaney, V. K., \& Danowski, K. (2015). Mixed foundations: Supporting and empowering multiracial student organizations. JCSCORE, 1(2), 54-85. https://doi.org/10.15763/issn.2642-2387.2015.1.2.54-85

Merriam, S. B. (2009). Qualitative research: A guide to design and implementation. Jossey-Bass.

Milner IV, H. R. (2007). Race, culture, and researcher positionality: Working through dangers seen, unseen, and unforeseen. Educational researcher, 36(7), 388-400. https://doi.org/10.3102/0013189X07309471

Montgomery, M. R. (2017). Identity politics of difference: The mixed-race American Indian experience. University Press of Colorado

Museus, S. D., Sariñana, S. A. L., \& Ryan, T. K. (2015). A qualitative examination of multiracial students' coping responses to experiences with prejudice and discrimination in college. Journal of College Student Development, 56(4), 331348. https://doi.org/10.1353/csd.2015.0041

Museus, S. D., Sariñana, S. A. L., Yee, A. L., \& Robinson, T. E. (2016). A qualitative analysis of multiracial students' experiences with prejudice and discrimination in college. Journal of College Student Development, 57(6), 680-697. https://doi.org/10.1353/csd.2016.0068

Olivo, V. B., \& Cepeda, R. (2021). A call for the examination of multiracial students in Minority Serving Institutions. New Directions for Student Services, 2021(174), 1520. https://doi.org/10.1002/ss.20383

Onorato, S., \& Musoba, G. D. (2015). La líder: Developing a leadership identity as a Hispanic woman at a Hispanic-Serving Institution. Journal of College Student Development, 56(1), 15-31. http://doi.org/10.1353/csd.2015.0003

Osei-Kofi, N. (2012). Identity, fluidity, and groupism: The construction of multiraciality in education discourse. Review of Education, Pedagogy, and Cultural Studies, 34(5), 245-257. https://doi.org/10.1080/10714413.2012.732782

Renn, K. A. (2000). Patterns of situational identity among biracial and multiracial college students. The review of higher education, 23(4), 399-420.

https://doi.org/10.1353/rhe.2000.0019 
Journal Committed to Social Change on Race and Ethnicity | Volume 7, Issue 2 | 2021

Renn, K. A. (2004). Mixed race students in college: The ecology of race, identity, and community. SUNY Press.

Renn, K. A. (2008). Research on bi-and multiracial identity development: Overview and synthesis. New Directions for Student Services, 123, 13-21. http://doi.org/10.1002/ss.282

Renn, K. A. (2009). Education policy, politics, and mixed heritage students in the United States. Journal of Social Issues, 65(1), 165-183. https://doi.org/10.1111/j.1540-4560.2008.01593.x

Renn, K. A., \& Arnold, K. D. (2003). Reconceptualizing research on college student peer culture. The journal of higher education, 74(3), 261-291. https://doi.org/10.1080/00221546.2003.11780847

Salinas Jr, C. (2020). The complexity of the "x" in Latinx: How Latinx/a/o students relate to, identify with, and understand the term Latinx. Journal of Hispanic Higher Education, 19(2), 149-168. https://doi.org/10.1177\%2F1538192719900382

Salinas Jr, C. \& Lozano, A. (2021). History and Evolution of the term Latinx. In E. G. Murillo, D. Delgado Bernal, S. Morales, L. Urrieta, E. Ruiz Bybee, J. Sánchez Muñoz, V. B. Saenz, D. Villanueva, M. Machado-Casas, \& K. Espinoza (Eds.), Handbook of Latinos and Education (second edition), (pp. 249-263). Rutledge.

Salinas Jr, C., \& Lozano, A. (2019). Mapping and recontextualizing the evolution of the term Latinx: An environmental scanning in higher education. Journal of Latinos and Education, 18(4), 302-315. https://doi.org/10.1080/15348431.2017.1390464

Sanchez, M. E. (2019). Perceptions of campus climate and experiences of racial microaggressions for Latinos at Hispanic-Serving Institutions. Journal of Hispanic Higher Education, 18(3), 240-253. https://doi.org/10.1177/1538192717739351

Santiago, D. A. (2006). Inventing Hispanic-serving institutions (HSIs): The basics. Excelencia in Education.

Serrano, U. (2020). 'Finding home': Campus racial microclimates and academic homeplaces at a Hispanic-Serving Institution Race Ethnicity and Education. https://doi.org/10.1080/13613324.2020.1718086

Stake, R. E. (2006). Multiple case study analysis. Guilford Press.

Yin, R. K. (2009). Case study research: Design and methods (4th ed.). SAGE.

Yin, R. K. (2012). Applications of case study research (3rd ed.). SAGE. 